Disclosure of Interests: None declared

DOI: 10.1136/annrheumdis-2020-eular.6206

\section{SAT0210 1 FACTORS ASSOCIATED WITH TIME TO SEVERE LUPUS NEPHRITIS IN A COHORT OF COLOMBIAN PATIENTS}

S. Herrera $^{1}$, J. C. Diaz-Coronado ${ }^{1,2}$, D. Rojas-Gualdrón ${ }^{3}$, L. Betancur-Vasquez ${ }^{2}$, D. Gonzalez-Hurtado ${ }^{2}$, J. Gonzalez-Arango ${ }^{2}$, L. Uribe-Arango ${ }^{2}$, M. F. Saavedra Chacón $^{2}$, J. Lacouture-Fierro², S. Monsalve ${ }^{2}$, S. Guerra-Zarama², J. D. Lopez², J. D. Serna ${ }^{2}$, J. Barbosa ${ }^{2}$, A. Sierra ${ }^{3}$, D. Hernandez-Parra ${ }^{1}$, R. Pineda-Tamayo ${ }^{1}$. ${ }^{1}$ Artmedica IPS, Grupo de información clínica, Medell ín, Colombia; ${ }^{2}$ CES University, Departamento medicina interna, Medellín, Colombia; ${ }^{3}$ CES University, Facultad de medicina, Medellin, Colombia

Background: Systemic lupus erythematosus (SLE) clinical manifestations, and their severity, vary according to age, ethnicity and socioeconomic status. Both Hispanic and Afro-Americans have a higher incidence and more sever presentation when compared to Caucasian patients with SLE

Objectives: To analyze clinical and immunological characteristics associated with time to severe renal involvement in patients with Systemic Lupus Erythematous in a Colombian cohort followed for one year, between January 2015 and December 2018 Methods: Retrospective follow-up study based in clinical records. Patients with SLE diagnosis that fulfilled either 1987 American College of Rheumatology Classification Criteria for SLE or 2011 Systemic Lupus International Collaborating Clinics (SLICC) classification criteria for SLE. We included patients with diagnosis of lupus nephritis according to Wallace and Dubois criteria. Patients who did not have at least two follow-up measurements or had a cause of nephritis other than lupus were excluded. The main outcome was defined as time from diagnosis to sever renal involvement defined as creatinine clearance $\leq 50 \mathrm{ml} / \mathrm{min}$, 24-hour proteinuria $\geq 3.5$ grams o end stage renal disease.

We analyzed clinical and immunological characteristics. Descriptive statistical analyses of participant data during the first evaluation are reported as frequencies and percentages for categorical variables, and as medians and interquartile ranges (IQR) for quantitative variables. Age and sex adjusted survival functions and Hazard ratios (HR) with 95\% confidence intervals and $p$-values were estimated using parametric Weibull models por interval-censored data. P values < 0.05 were considered statistically significant

Results: 548 patients were analyzed: 67 were left-censored as they presented renal involvement at entry, 6 were interval censored as outcome occurred between study visits, and 475 were right-censored as involvement was not registered during follow-up. 529 (96.5\%) patients were female, median age at entry was $46(I Q R=23)$ and median age to diagnosis was $29.5(I Q R=20.6) .67 \%$ were mestizo, $13 \%$ Caucasian and $0.3 \%$ Afro-Colombian. Age and sex adjusted variables associated with time to severe lupus nephritis were high blood pressure $\mathrm{HR}=3.5(95 \% \mathrm{Cl} 2.2-5.6$; $\mathrm{p}$-value $<0.001)$ and Anti-RO (per unit increase) $\mathrm{HR}=$ $1.002(95 \% \mathrm{Cl} 1.001-1.004 ; p$-value $=0.04)$. Figure 1 shows age and sex adjusted survival function.

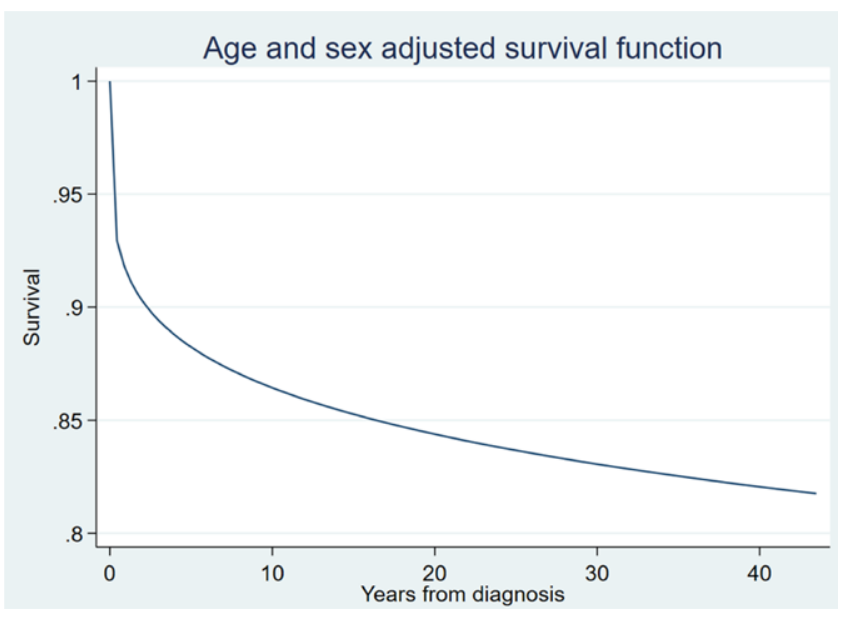

Conclusion: In our cohort the appearance of severe lupus nephritis occurs in less than $15 \%$ of patients at 10 years. Both high blood pressure and elevated anti-Ro titers were associated with a higher rate of onset in the presentation of severe lupus nephritis, as seen in some polymorphs of anti Ro.

References:

Disclosure of Interests: Sebastian Herrera Speakers bureau: academic conference, Juan camilo Diaz-Coronado: None declared, Diego Rojas-Gualdrón: None declared, Laura Betancur-Vasquez: None declared, Daniel Gonzalez-Hurtado: None declared, Juanita Gonzalez-Arango: None declared, laura Uribe-Arango: None declared, Maria Fernanda Saavedra Chacón: None declared, Jorge Lacouture-Fierro: None declared, Santiago Monsalve: None declared, Sebastian Guerra-Zarama: None declared, Juan david Lopez: None declared, Juan david Serna: None declared, Julian Barbosa: None declared, Ana Sierra: None declared, Deicy Hernandez-Parra: None declared, Ricardo Pineda.Tamayo: None declared DOI: 10.1136/annrheumdis-2020-eular.6282

\section{\begin{tabular}{|l|l}
\hline SAT0211 RENAL INJURY IN SYSTEMIC LUPUS \\
\hline
\end{tabular} ERYTHEMATOSUS CHARACTERIZED BY THROMBOTIC MICROANGIOPATHY}

W. Hu ${ }^{1} .{ }^{1}$ Jinling Hospital, National Clinical Research Center of Kidney Diseases, Jilin, China

Background: Classical lupus nephritis (LN) is characterized by glomerular immune complex(IC) deposition with glomerular proliferation, basement membrane destruction and cell infiltration. Non-IC mediated renal injury with thrombotic microangiopathy (TMA) was also reported in patients with systemic lupus erythematosus (SLE-renal TMA), but most studies were reported in patients with both LN and renal TMA Objectives: In this study, clinical features and outcomes of SLE-renal TMA in absence of obvious IC in SLE patients were analyzed.

Methods: Patients with glomerular TMA and/or vascular TMA in the absence of obvious subendothelial or epithelial immune deposits were screened out from 2332 biopsied in SLE patients who underwent first renal biopsy from January 2005 to August 2016. Their clinical, histological features and outcomes were retrospectively analyzed. Results: In 2332 renal biopsies obtained from SLE patients, 257 (11.0\%) showed renal TMA, of which 237 showed both renal TMA and LN, and 20 biopsies had only renal TMA (SLE-renal TMA). There were 2 males and 18 females with an average age of $(25 \pm 10)$ years. The median course of SLE and LN were $3.0(1.0,6.0)$ and $0.8(0.5,1.9)$ months. All 20 patients deserved acute kidney injury, of which 11 (55\%) needed renal replacement therapy (RRT) and $12(60 \%)$ were nephrotic syndrome. Blood system involvement was found in all cases, including 13 cases $(65.0 \%)$ with TMA triad (microvascular hemolytic anemia, thrombocytopenia and elevated lactate dehydrogenase). Pathological examination showed that 17 cases $(85.0 \%)$ had both glomerular TMA and vascular TMA. Immunofluorescence and electron microscopy showed that 8 cases $(40 \%)$ had no IC deposition in glomerulus and 12 cases $(60 \%)$ had only IC deposition in mesangium. Acute tubulointerstitial lesions in patients requiring RRT were more serious than those no needing for RRT((43.6 24.9$) \%$ vs $(21.7 \pm 20.1) \%, P=0.047)$. The fusion range of foot process was positively correlated with proteinuria $\left(r^{2}=0.347, P=0.006\right)$.

All patients received high-dose methylprednisolone pulse therapy. Four patients received plasma exchange and three patients received gamma globulin, respectively. Eleven patients requiring RRT all stop RRT in a median time of $16.0(9.0,30.0)$ days During a median follow-up of $58.0(36.0,92.3)$ months, complete remission (CR) was obtained in 15 cases, partial remission in 4 cases and no remission in 1 case. Six cases $(30 \%)$ relapsed. No case died or progressed to end stage renal disease.

Conclusion: Renal injury characterized by TMA is not uncommon in SLE renal biopsy cases. The clinical manifestation is special and the renal injury is serious. The renal outcome is good by intensive immunosuppressive therapy. It should be considered as a unique type of renal injury in SLE.

References:

[1] Moake JL. Thrombotic microangiopathies. N Engl J Med. 2002. 347(8): 589-600.

[2] Anders HJ, Weening JJ. Kidney disease in lupus is not always 'lupus nephritis' Arthritis Res Ther. 2013. 15(2): 108.

[3] Song D, Wu LH, Wang FM, et al. The spectrum of renal thrombotic microangiopathy in lupus nephritis. Arthritis Res Ther. 2013. 15(1): R12.

[4] Hu WX, Liu ZZ, Chen HP, Zhang HT, Li LS, Liu ZH. Clinical characteristics and prognosis of diffuse proliferative lupus nephritis with thrombotic microangiopathy. Lupus. 2010. 19(14): 1591-8.

[5] Tomov S, Lazarchick J, Self SE, Bruner ET, Budisavljevic MN. Kidney-limited thrombotic microangiopathy in patients with SLE treated with romiplostim. Lupus. 2013. 22(5): 504-9.

[6] Li C, Yap D, Chan G, et al. Clinical Outcomes and Clinico-pathological Correlations in Lupus Nephritis with Kidney Biopsy Showing Thrombotic Microangiopathy. J Rheumatol. 2019

[7] Chen $\mathrm{MH}$, Chen $\mathrm{MH}$, Chen WS, et al. Thrombotic microangiopathy in systemic lupus erythematosus: a cohort study in North Taiwan. Rheumatology (Oxford). 2011. 50(4): 768-75.

[8] Park MH, AUID- Oho, Caselman N, Ulmer S, Weitz IC, AUID- Oho. Complement-mediated thrombotic microangiopathy associated with lupus nephritis. Blood Adv. 2018. 2(16): 2090-2094.

Disclosure of Interests: None declared

DOI: 10.1136/annrheumdis-2020-eular.1198 